\title{
Spinal prilocaine for same-day surgery: the importance of equipotent doses
}

\author{
Emmanuel Guntz, MD, PhD • Yota Kapessidou, MD, PhD
}

Received: 17 February 2016/Revised: 10 March 2016/Accepted: 29 March 2016/Published online: 4 April 2016

(C) Canadian Anesthesiologists' Society 2016

\section{To the Editor,}

We read with interest both the article published by Aguirre et al. regarding the comparison of intrathecal $2 \%$ hyperbaric prilocaine with ropivacaine for patients undergoing knee arthroscopy ${ }^{1}$ and the following discussion of Manassero et al. ${ }^{2}$ We believe that this exchange of opinions highlights the importance of administering doses of local anesthetics tailored to a particular clinical setting.

The increasing volume of ambulatory surgery has recently led to more research on short-acting and intermediate-acting local anesthetics. Clinicians can now choose between anesthetics to fine-tune spinal anesthesia according to the length of the surgery. In regard to this concept, the dose of spinally administered hyperbaric prilocaine must be precisely defined. Some studies have compared various arbitrarily chosen doses of prilocaine with other local anesthetics in various clinical settings without always taking into account the equipotent doses of these anesthetics. ${ }^{1}$

Hyperbaric prilocaine is an intermediate-acting local anesthetic. Increasing the dose prolongs the duration of sensory and motor block. High doses provide blocks whose durations are comparable to those obtained with low doses of long-acting local anesthetics such as ropivacaine or bupivacaine, but they could induce adverse effects. Kreutziger et al. showed that $60 \mathrm{mg}$ of hyperbaric

E. Guntz, MD, PhD ( $ه)$

Department of Anesthesiology, Hôpital Braine l'Alleud

Waterloo, Université Libre de Bruxelles (ULB), Brussels,

Belgium

e-mail: eguntz@ulb.ac.be

Y. Kapessidou, MD, PhD

CHU St Pierre, ULB, Brussels, Belgium prilocaine caused urinary retention in $23 \%$ of patients. ${ }^{3}$ On the contrary, decreasing the dose of hyperbaric prilocaine shortens the duration of the sensory and motor blocks but may lead to block failure depending on the desired sensory block level. ${ }^{4}$

In our previously published study, we determined the effective doses $\left(\mathrm{ED}_{50}\right.$ and $\left.\mathrm{ED}_{90}\right)$ of intrathecal hyperbaric prilocaine for patients undergoing ambulatory knee arthroscopy. ${ }^{5}$ The minimum effective dose for patients undergoing knee arthroscopy $\left(\mathrm{ED}_{50}\right)$ of hyperbaric $2 \%$ prilocaine was $28.9 \mathrm{mg}$, whereas the $\mathrm{ED}_{90}$ was $38.5 \mathrm{mg}$. In our study, all patients met the discharge criteria after 205 min and could spontaneously urinate.

Moreover, the regression model we employed for statistical analysis suggested that $50 \mathrm{mg}$ was the optimal clinical dose for knee arthroscopy. Indeed, with doses $<50$ $\mathrm{mg}$, the patient could be exposed to block failure. Larger doses provided no gain in terms of successful spinal anesthesia and increased the side effects. ${ }^{4}$

The comparison of local anesthetics in particular clinical settings should be performed using equipotent doses. Thus, for some of the earlier local anesthetics with a new formulation (e.g., hyperbaric prilocaine and chloroprocaine), $\mathrm{ED}_{90}$ must be known and used.

Conflict of interest None declared.

Editorial reponsibility This submission was handled by Dr. Philip M. Jones, Associate Editor, Canadian Journal of Anesthesia.

\section{References}

1. Aguirre J, Borgeat A, Buhler P, Mrdjen J, Hardmeier B, Bonvini $J M$. Intrathecal hyperbaric $2 \%$ prilocaine versus $0.4 \%$ plain 
ropivacaine for same-day arthroscopic knee surgery: a prospective randomized double-blind controlled study. Can. J Anesth 2015; 62: 1055-62.

2. Manassero A, Meconi T, Fanelli A. Is $60 \mathrm{mg}$ a suitable dosage for same-day spinal prilocaine? Can J Anesth 2016; DOI:10.1007/ s12630-015-0554-1.

3. Kreutziger J, Frankenberger B, Luger TJ, Richard S, Zbinden S. Urinary retention after spinal anaesthesia with hyperbaric prilocaine $2 \%$ in an ambulatory setting. Br J Anaesth 2010; 104: $582-6$.
4. Camponovo C, Fanelli A, Ghisi D, Cristina D, Fanelli G. A prospective, double-blinded, randomized, clinical trial comparing the efficacy of $40 \mathrm{mg}$ and $60 \mathrm{mg}$ hyperbaric $2 \%$ prilocaine versus $60 \mathrm{mg}$ plain $2 \%$ prilocaine for intrathecal anesthesia in ambulatory surgery. Anesth Analg 2010; 111: 568-72.

5. Guntz E, Latrech B, Tsiberidis C, Gouwy J, Kapessidou Y. ED50 and ED90 of intrathecal hyperbaric $2 \%$ prilocaine in ambulatory knee arthroscopy. Can J Anesth 2014; 61: 801-7. 